\title{
NIH Minipig
}

National Cancer Institute

\section{Source}

National Cancer Institute. NIH Minipig. NCI Thesaurus. Code C106549.

An inbred strain of miniature swine developed by Sachs et al at the NIH in 1976 from a cross between a Hormel pig and a Vita Vet miniature pig. 